\title{
RESEÑA. COMO VAYA YO Y LO ENCUENTRE. FEMINISMO ANDALUZ Y OTRAS PRENDAS QUE TÚ NO VEÍAS
}

\author{
REVIEW. COMO VAYA YO Y LO ENCUENTRE. FEMINISMO ANDALUZ Y \\ OTRAS PRENDAS QUE TÚ NO VEÍAS
}

\section{RESENHA. COMO VAYA YO Y LO ENCUENTRE. FEMINISMO ANDALUZ Y OTRAS PRENDAS QUE TÚ NO VEÍAS}

\author{
Begoña Sánchez Torrejón \\ Universidad de Cádiz, España \\ https://orcid.org/0000-0002-1242-4172 \\ begonia.sanchez@uca.es
}

Recibido:31/08/2020 Revisado: 07/09/2020 Aceptado:07/09/2020 Publicado:01/11/2020

Autor: Mar Gallego

Editorial: Libros.com, Jaén

Año: 2020

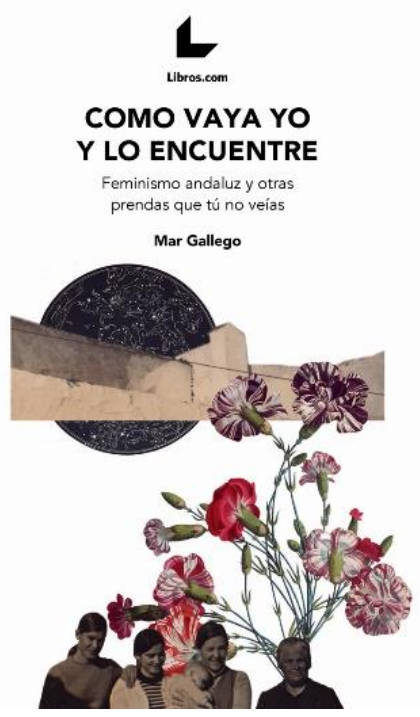

Cómo citar esta reseña: Sánchez, B. (2020). Reseña. Como vaya yo y lo encuentre. Feminismo andaluz y otras prendas que tú no veías. Hachetetepé. Revista científica en Educación y Comunicación, (21), 101-103. https://doi.org/10.25267/Hachetetepe.2020.i21.11

Este maravilloso ensayo sobre feminismo andaluz y mujeres andaluzas escrito por la periodista Mar Gallego y presentado en perfecto andaluz, nos retrata varias historias de nuestras madres, abuelas y bisabuelas; historias que a todas y a todos nos retumban hoy día y nos remueven desde lo jondo, homenaje merecido a nuestras olvidadas ancestras, de las que tanto tenemos que aprender, lectura recomendable para estos tiempos, para que no se nos olvide de dónde venimos y hacia dónde vamos. La autora nos plantea que detrás de aquello que nunca directamente miramos hay una maravillosa oportunidad para empezar a construir otra realidad más igualitaria. 
A través de diversas historias, como ya hemos señalado las protagonistas son nuestras madres, abuelas y bisabuelas presentadas como luchadoras incansables de realidades difíciles, la autora nos lleva a reflexionar sobre la necesidad de comenzar a resignificar los cuidados $\mathrm{y}$, sobre todo, a ponerlos en la base de nuestras actuales prioridades. El texto pone de manifiesto en el contexto de las condiciones socioeconómicas de Andalucía, cómo el sistema heteropatriarcal delega estas funciones a cargo de las mujeres. Visibilizar a estas grandes mujeres de la sociedad, ocultas en el imaginario social, es una cuenta pendiente que debemos saldar desde las propias mujeres que ponen su voz, cartografiando realidades veladas por el patriarcado y la territorialidad imperante.

Siguiendo al hilo de comentado anteriormente, este libro nos invita a reconocer el cuidado como una necesidad central en la sociedad actual, que debe ser valorado como tal y asumido por todos los miembros de la sociedad, en igualdad entre hombres y mujeres, para que deje de ser tarea obligatoria y desvalorizada de las mujeres. Nos recuerda que necesitamos cuidados mutuos entre todos y todas, estos humanizan a las personas y a las sociedades, y se valoran como eje de una sociedad democrática. No podemos construir una sociedad basada en valores que desprestigian estas funciones, soslayando las relaciones afectivas de estas y poniendo el alza su importancia. Los cuidados deben ser una de las bases de nuestra sociedad, deben estar basados en la igualdad entre los diversos miembros que forman la comunidad, donde uno de los parámetros en los que se basa los valores sociales sean los afectos, sin ninguna discriminación de género, clase social o de raza. Se pone en primera plana un tema actual, desde el prisma de la deslegitimación del discurso que menosprecia a las mujeres campesinas y obreras que son el sustento social, y quienes realizan en silencio los cuidados y afectos de la sociedad.

En este precursor alegato desde la identidad andaluza, se plantea un feminismo cercano, de nuestras realidades circundantes, que recuerda el carácter de la interseccionalidad, que cruza a los feminismos. Mar Gallego nos invita a poner nuestra mirada en lo cercano, desde la idiosincrasia andaluza campesina y obrera para empezar a vislumbrar la realidad oculta y relegada, dignificando los saberes de nuestras predecesoras para empezar a valorar identidades desvalorizadas por el patriarcado y el centralismo. A lo largo de sus páginas, las diversas historias reales muestran la riqueza de las grandes olvidadas, las mujeres obreras andaluzas, tanto de su gran labor y aportaciones en el espacio privado como en el espacio público.

El libro se plantea como un texto referente en el feminismo andaluz, los delantales, los patios de vecinos, las corralas... recobran el valor incalculable de su legado cultural y de género, cuyo gran valor habíamos olvidado. En estos últimos años como refleja el texto con sus múltiples alusiones, estamos observando el florecimiento de un feminismo con impronta andaluza, con elementos y características propias.

Podemos descubrir entre sus líneas, el cuestionamiento que se plantea frente al feminismo hegemónico, de tinte blanco, heteronormativo, de carácter occidental y que legitima el relato de la historia de algunas mujeres, invisibilizando gran parte de las mujeres andaluzas. Debatiendo al feminismo que no ha sabido responder ni darnos todas las herramientas que necesitamos para analizar las realidades de las mujeres andaluzas. En sus páginas podemos ver la necesaria reivindicación que la autora plantea como lo personal se hace político, desde su propia experiencia cuando le ponemos palabras de realidades ocultas por los discursos hegemónicos. La reflexión que plantea, 
apuesta por recuperar las historias calladas por el patriarcado, cargadas de conciencia de clase, historias necesarias para poder construir nuestras vidas y nuestros caminos y luchas futuras. Las historias que revelan nuestras ancestras en esta obra, ponen en tela de juicio el actual pensamiento patriarcal, colonial y discriminatorio, haciéndolas más actuales que nunca.

La urgente necesidad de empezar a tumbar los mitos y estereotipos sobre las mujeres andaluzas, basados en la andaluzofobia, nos lleva a deconstruir el exotismo y minusvaloración con el que nos han dibujado. El planteamiento de la autora no surge como una respuesta que confronta al feminismo hegemónico e imperante sino como una propuesta colectiva e identitaria que requiera del trabajo conjunto desde la perspectiva de la territorialidad. Comenzar a visibilizar con acento andaluz, realidades de primera mano, para reivindicar una sociedad más igualitaria como sujetos políticos con identidad propia. Revalorizando la identidad andaluza como elemento identificativo, poniendo nuestra mirada y comenzar a dar valor a la identidad andaluza a través de nuestras olvidadas ancestras, cuyos saberes han sufrido a lo largo de la historia el ostracismo histórico.

Empezar a vernos nosotras mismas desde el prisma de nuestras predecesoras andaluzas, postulando un feminismo colectivo con tintes andaluces, es uno de los grandes retos que nos propone la autora. Reconociéndonos en los denominadores comunes que nos atraviesan a todas y a todos y que dan posibles respuestas a nuestra actual realidad, abordándolo de forma colectiva para entender los múltiples crisoles de las experiencias que se han ocultado a lo largo de nuestra historia, desde la más antigua hasta la actual. Por todo ello, escuchar las voces y los quejidos que nos invita este maravilloso ensayo a través de las intersecciones que nos atraviesan, es clave para construir colectivamente desde la igualdad y la libertad nuestras propias historias, tan necesarias para poder seguir avanzando en democracia.

\section{REFERENCIA BIBLIOGRÁFICA}

Gallego, M. (2020). Como vaya yo y lo encuentre. Feminismo andaluz y otras prendas que tú no veías. Jaén: Libros.com. 